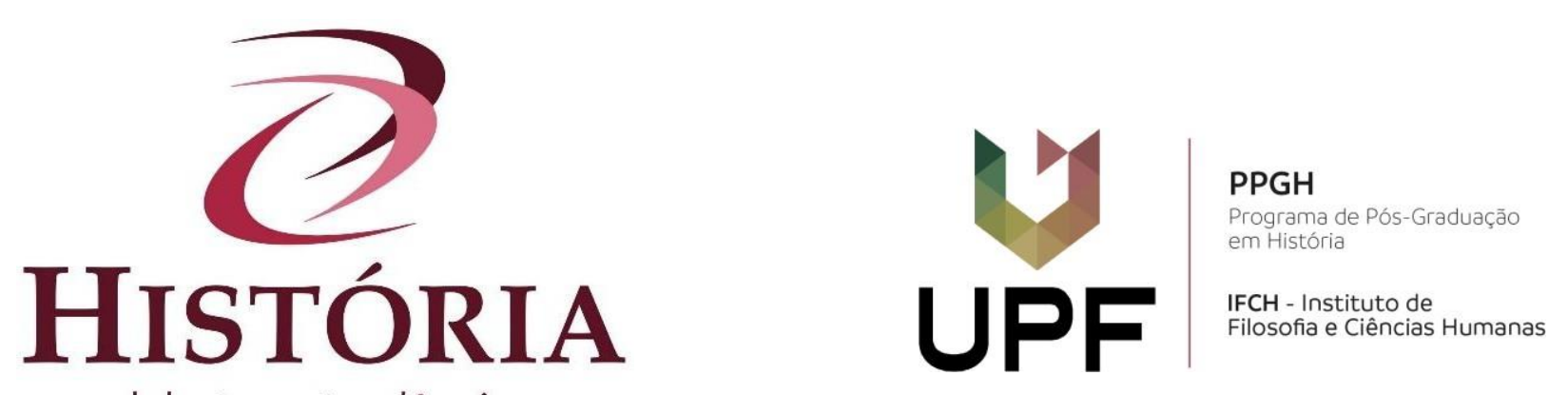

debates e tendências

\title{
Ditadura Militar Brasileira: o aparelhamento do sistema repressivo e a fabricação do informante
}

Brazilian Military Dictatorship: the rigging of the repressive system and the informant's fabrication

Dictadura Militar Brasileña: el aparejamiento del sistema represivo y la fabricación del informante

Resumo: A Ditadura Militar instaurada por meio de um golpe de Estado, em 1964, pôs fim à jovem democracia brasileira iniciada em 1945. Para manterem-se no poder e garantir a legitimidade política e social, os militares aprimoraram os órgãos de repressão existentes no Brasil e criaram outros mecanismos de vigilância e repressão no intuito de manter o controle e a censura na sociedade. O presente artigo propõe uma análise sobre esse período de exceção brasileiro enfatizando, no contexto ditatorial, a organização do aparelho repressivo do Estado e o papel do informante dentro da dinâmica da repressão àqueles considerados subversivos pelos militares.

Palavras chave: Ditadura militar. Estado de exceção. Guerra psicológica. Repressão.

\begin{abstract}
The military dictatorship, established through a coup d'etat in 1964, ended the young Brazilian democracy initiated after 1945. To remain in power, and to ensure political legitimacy, the military improved the existing social control bodies in Brazil and created other mechanisms of repression in order to maintain vigilance and censorship in society. This article makes an analysis of this period of Brazilian exception emphasizing, in the dictatorial context, the organization of the repressive apparatus of the State and the role of the informant within the dynamics of repression to those considered subversive by the military.
\end{abstract}

Keywords: Exception State. Military dictatorship. Psychological warfare. Repression.

Resumen: La dictadura militar, instaurada por medio de un golpe de estado, en 1964, puso un fin a la joven democracia brasileña iniciada después de 1945. Para mantenerse en el poder, y garantizar la legitimidad política, los militares perfeccionaron los órganos de control social existentes en Brasil y crearon otros mecanismos de represión con el objetivo de mantener la vigilancia y la censura en la sociedad. El presente artículo hace un análisis de ese periodo de excepción brasileña enfatizando, en el contexto dictatorial, la organización del aparato represivo del Estado y el papel del informante dentro de la dinámica represiva contra los considerados subversivos por los militares. 
Palabras clave: Dictadura militar. Estado de excepción. Guerra psicológica. Represión.

\section{Introdução}

A vasta literatura sobre a máquina repressiva do Estado, em particular a que trata da Ditadura Militar, tem chamado atenção para a violência e os seus excessos praticados contra os indivíduos contrários à ordem estabelecida. Um tipo de violência extrema que eliminou presos políticos, não mediu esforços para calar inúmeras vozes e exilar tantas outras que consideravam ser destoantes do governo. A filósofa alemã Hannah Arendt (2009), em um importante texto, lembra que a violência decorre do instante em que a política se extingue. Em outras palavras, a política, que é a capacidade de agir em conjunto e requer o consenso de muitos para se efetivar uma ação, desaparece quando a violência e sua glorificação anulam a faculdade de agir no mundo e de criar nele algo novo.

De acordo com a filosofia política arendtiana, a violência se assenta em implementos que multiplicam e ampliam com instrumentos e tecnologia, o vigor humano designa algo no singular como o vigor físico de um indivíduo. Por isso, a forma extrema de violência é a de "Um contra todos" feita com frequência com o uso de instrumentos e por meio de um aparelho repressivo altamente burocratizado. Não se realiza sem uma base de poder e de apoio a exemplo do que ocorreu durante o sistema totalitário com a criação da polícia secreta e da sua rede de informantes.

Outra reflexão partiu do filósofo italiano Giorgio Agamben (2004; 2007), particularmente no que tange à análise das leis que atribuiu excessivo poder político ao Executivo e lhe conferiu a capacidade de decisões em nome da sociedade. Analisando a permanência do estado de exceção no fenômeno jurídico das democracias contemporâneas, o filósofo procurou entender a atualidade do estado de exceção na lógica das democracias ocidentais e sua dúbia relação entre direito e violência. O paradoxo se expressa na relação de correspondência entre estado de exceção e soberania.

O soberano, enquanto poder que decide e suspende a norma, está fora do direito, embora pertença ao ordenamento jurídico porque, segundo consta, possui a competência para a decisão, elemento fundamental do direito. É ele, o soberano, quem decide o que é o interesse público e o bem comum, ou seja, é quem estabelece o que é segurança e paz (AGAMBEN, 2007). De acordo com esta perspectiva, o ordenamento jurídico contém em si o seu contrário quando admite, pela suspensão do direito, uma violência não regulada pela Lei. Neste caso, não mais ao Legislativo compete a função de legislar, mas a de limitarse a ratificar decretos do Executivo (AGAMBEN, 2004), a exemplo dos regimes ditatoriais no Brasil e na América Latina. 
Para que essa lógica pudesse funcionar, os dispositivos de controle e de vigilância tornaram-se comum, como paradigma de segurança e como técnica normal de governo, nas democracias após a Primeira Guerra Mundial. Nasceram com o intuito de garantir a segurança pública e a ordem. Em momentos de emergência ou em casos de necessidades extremas, ficava nas mãos do Executivo legislar, sob a forma de decreto, as causas públicas (AGAMBEM, 2004, p. 11-49). Também ao Executivo, diante da possibilidade de ameaças, cabia estabelecer as regras e impor decisões consideradas importantes para a sociedade. Entre estas se incluía eliminar quem não estivesse integrado no sistema civil e aquele considerado inimigo do Estado. Neste momento, a metáfora bélica tornou-se parte integrante no vocabulário político, no decorrer do século XX, para justificar as formas de violência contra os cidadãos por meio do dispositivo da exceção.

Com base nessa reflexão, pretende-se no presente artigo analisar a configuração de um verdadeiro estado de exceção na dinâmica política do Brasil, instaurado durante a Ditadura Militar. Para legitimar sua ação, os militares aprimoraram os aparelhos repressivos já presentes no país desde a primeira metade do século XX, em que novos mecanismos legais e instrumentais foram criados para combater as oposições e garantir a permanência do governo. Todo o aparato funcionou não somente pelo apoio de oficiais, preparados para responder à lógica do sistema, mas também com o apoio de civis que se dispuseram a colaborar com o Regime.

\section{A “Guerra Psicológica"}

A Ditadura Militar de 1964 foi um golpe na jovem democracia brasileira iniciada, ainda com dificuldades, após 945. Mesclando autoritarismo e modernização conservadora, os militares que ascenderam ao poder eram antirreformistas, principalmente contra as reformas propostas pela esquerda, mas citavam reformas modernizantes como garantia do crescimento capitalista; consideravam-se revolucionários, mas desejavam manter a ordem social vigente, as hierarquias e as instituições tradicionais (NAPOLITANO, 2014, p. 313315). Prevaleceu, então, o viés conservador e anticomunista como cimento da coalização golpista, fazendo convergir posicionamentos políticos variados, entre os quais se destacaram os liberais, os anticomunistas, os antipopulistas, os empresários, os latifundiários e a grande imprensa, que caracterizaram o desafio, naquele primeiro momento, de se construir uma memória oficial para o golpe militar.

Gradativamente, pela modificação e pela criação de um aparato legal, os militares 
trabalharam para assegurar a legitimidade do Regime, tornando-o mais centralizador, repressivo e violento. Enquadraram-se, na dinâmica, os sucessivos "Atos Institucionais" cujo objetivo principal era o de garantir o reforço legal do Poder Executivo dentro do sistema político. Uma das medidas, especialmente no que tange à representação política, tem-se no Ato Institucional $\mathrm{N}^{\mathrm{o}} 2$ ao delegar ao Executivo o poder das cassações políticas:

\begin{abstract}
Art. 15 - No interesse de preservar e consolidar a Revolução, o Presidente da República, ouvindo o Conselho de Segurança Nacional, e sem as limitações previstas na Constituição, poderá suspender os direitos políticos de quaisquer cidadãos pelo prazo de $10(\mathrm{dez})$ anos e cassar mandatos legislativos federais, estaduais e municipais. Parágrafo único - Aos membros dos Legislativos federal, estaduais e municipais que tiverem seus mandatos cassados não serão dados substitutos, determinando-se o quorum parlamentar em função dos lugares efetivamente preenchidos (BRASIL, 1965)
\end{abstract}

Consagrou o processo de repressão, em dezembro de 1968, a promulgação do Ato Institucional $\mathrm{N}^{\mathrm{o}} 5$ e, no ano seguinte, a aprovação de uma nova Lei de Segurança Nacional, substituindo a de 1967, sendo aquela ainda mais rigorosa. Tais dispositivos de controle, normalizadores e com forte inclinação à violência, limitaram sobremaneira a liberdade de reunião, de associação e de imprensa, fazendo da questão da segurança e da defesa interna tema marcadamente presente durante a Ditadura Militar. Em seu nome se buscou formas de combater a subversão e reprimir, preventivamente, as modalidades de ameaças ao Estado. A partir desse momento passa a vigorar a lógica do inimigo interno e da defesa nacional (KUCINSKI, 1982, p. 18-19). Os militares estavam convencidos de que os contestadores nada mais eram do que membros de um exército inimigo que já havia conseguido se infiltrar no Brasil, trazendo a guerra externa para dentro da própria casa.

Essa concepção estava atrelada à ideia de "guerra psicológica”. Alexandre Nodari (2012) considera o aspecto importante porque foi por meio dele que a censura se baseou para realizar a proibição de peças teatrais, livros, filmes e jornais. O medo era o de que o comunismo pudesse criar um clima emocional perigoso no país e iniciar um processo revolucionário a exemplo de Cuba. Neste jogo, preponderante foi o papel da propaganda como ferramenta de comunicação e veículo de propagação de efeitos sensíveis na população e de mobilização da opinião pública. Embora esta seja uma característica presente nas Leis de segurança nacional promulgadas no Regime de 1964, as primeiras noções semelhantes a uma "guerra psicológica" encontraram-se, ainda na década de 1950, nos estudos elaborados pela Escola Superior de Guerra (ESG), onde se forjou a doutrina de segurança nacional. Com assessoria dos Estados Unidos, a ESG foi criada em 1949, com o objetivo de formar os quadros permanentes das Forças Armadas e oferecer cursos sobre informações e a promover palestras e conferências com especialistas na área. Foi também nesta Escola que o conceito de Guerra Revolucionária foi introduzido no Brasil pelo general Augusto Fragoso, em 1959. 
Uma forma de atuar na sociedade para colocar em prática a ideia de "guerra gica” era pelo poder psicossocial. De acordo com os textos teóricos publicados pela Biblioteca do Exército, o poder psicossocial era um importante componente do poder nacional. Expressava-se nos fenômenos sociais e psicológicos e tinha na população, o elemento a ser estudado (GURGEL, 1975, p. 110). Nesta configuração, outra questão adquiriu importância. Trata-se do binômio segurança/desenvolvimento. Durante as décadas de 1940, 1950 e 1960, o desenvolvimento fora a linguagem política comum no mundo e, de modo particular, nos países da América Latina. No contexto de Guerra Fria, a concepção de segurança era o requisito para contrapor-se ao comunismo. Neste período, permaneceu a ideia de que a salvação do mundo estaria no desenvolvimento e seu tema comum era o crescimento norteado pela visão de que a evolução técnica e econômica garantiria o avanço da democracia, a prosperidade, a felicidade e o bem-estar da humanidade (MORIN, 2010, p. 29). Nortearam as Leis de segurança:

I) A Segurança Nacional é uma função mais do Potencial Geral da Nação do que de seu Potencial Militar. II) O Brasil possui os requisitos básicos (área, população, recursos) indispensáveis para se tornar uma grande potência. III) O desenvolvimento do Brasil tem sido retardado por motivos suscetíveis de remoção. IV) Como todo trabalho, a obtenção dessa aceleração exige a utilização de uma energia motriz e de um processo de aplicação dessa energia. V) $\mathrm{O}$ impedimento até agora existente contra o surgimento de soluções nacionais para os problemas brasileiros é devido ao processo de ampliação de energia adotado e à falta de hábito de trabalho em conjunto. VI) Urge substituir o método dos pareceres por outro método que permita chegar-se a soluções harmônicas e equilibradas. VII) O instrumento a utilizar para a elaboração de novo método a adotar e para a sua difusão consiste na criação de um instituto nacional de altos estudos, funcionando como centro permanente de pesquisas (GURGEL, 1975, p. 30-31).

Com base na estratégia psicossocial e na elaboração do discurso desenvolvimentista e de segurança, o Regime Militar procurou estabelecer as bases de legitimidade política no intuito de obter o consenso social, de modo que os militares procurassem se identificar com a população, sobretudo pela exaltação e a preservação dos valores já inscritos no imaginário social: a família, a religião católica, a pátria, a ordem e a disciplina. A legitimidade do Regime passava pela alocação destes valores como mecanismos de padronização das relações sociais. Seus aspectos eram trabalhados e sentidos nas diferentes áreas da vida social que iam desde a reformulação de currículos escolares à propaganda nos meios de comunicação de grande alcance social.

A partir desse momento, as Forças Armadas se encarregaram de criar um conjunto de ações, entre elas, o investimento na formação dos oficiais, na publicação de textos com uma abordagem teórica para esclarecer os militares sobre o tema da vigilância, segurança e obtenção de informações, e na publicação de livros e panfletos destinados ao público mais amplo (QUADRAT, 2012). Em relação ao conceito de inimigo interno, pode-se dizer que se estimulou o ódio, a agressividade e a destrutividade em nome da defesa. Para combater 
o novo tipo de inimigo, os militares concentraram seus esforços na construção de dispositivos capazes de frear o avanço do perigo comunista e impedir sua influência política e moral na sociedade.

É importante lembrar que os militares não tinham um projeto claro de governo quando tomaram o poder. Entre as Forças Armadas havia tensões políticas e disputas de poder em relação ao modelo de projeto de governo adequado para o Brasil. Isso explica, em grande medida, a forma como se deu o combate às oposições na Ditadura (CODATO, 2004). Por conta dessa dinâmica, a Ditadura foi marcada por ciclos de repressão e de liberalização e pela gradativa militarização do sistema estatal, conforme demonstra o quadro abaixo:

\begin{tabular}{|l|l|}
\hline \multicolumn{1}{|c|}{ CICLO DE "REPRESSÃO" } & \multicolumn{1}{|c|}{ CICLO DE "LIBERALIZAÇãO" } \\
\hline $\begin{array}{l}\text { 1) 1964-1965: eliminação dos atores ligados ao } \\
\text { populismo (líderes partidários, sindicais) e a posição } \\
\text { de "esquerda" em geral (AI-2); }\end{array}$ & $\begin{array}{l}\text { 1) 1965: adoção de uma "política de retorno à } \\
\text { normalidade" pelo governo Castello branco, a fim } \\
\text { de "constitucionalizar" o regime (AI-4); }\end{array}$ \\
\hline $\begin{array}{l}\text { 2) 1966-1967: consumação dos expurgos políticos } \\
\text { após a edição do Ato Institucional n. 2 em novembro } \\
\text { de 1965; }\end{array}$ & $\begin{array}{l}\text { 2) 1967-1968: adoção da "política de alívio" pelo } \\
\text { governo de Costa e Silva, que envolvia tentativas } \\
\text { de negociação com a oposição; }\end{array}$ \\
\hline $\begin{array}{l}\text { 3) 1969-1973: enfrentamentos com a luta armada e } \\
\text { constituição de um aparelho repressivo-militar; }\end{array}$ & $\begin{array}{l}\text { 3) 1974-1976: "política de distensão", adotada no } \\
\text { início do governo Geisel; }\end{array}$ \\
\hline $\begin{array}{l}\text { 4) 1975- 1976: concentração da repressão em São } \\
\text { Paulo a fim de enfrentar a emergência de grande } \\
\text { frente de oposição; }\end{array}$ & $\begin{array}{l}\text { 4) 1977-1979: retomada da "distensão" pelo } \\
\text { governo Geisel após o "pacote de abril" de 1977, } \\
\text { tendo como objeto final a revogação do Ato } \\
\text { Institucional n. 5; }\end{array}$ \\
\hline $\begin{array}{l}\text { 5) 1979-1984: repressão aos movimentos de } \\
\text { trabalhadores rurais e urbanos, principalmente, o } \\
\text { novo movimento sindical. }\end{array}$ & $\begin{array}{l}\text { 5) 1979-1984: continuidade da "política de de } \\
\text { distensão" na "política de abertura" do governo } \\
\text { Figueiredo. }\end{array}$ \\
\hline
\end{tabular}

Quadro 1: Ciclos políticos do regime ditatorial-militar (CODATO, 2004, p. 14).

Percebe-se, com isso, que a violência se tornara parte constitutiva do novo regime político. A lógica do inimigo interno, com o seu potencial de agressividade e de destrutividade, imposta pela Doutrina de Segurança Nacional, e a própria implantação da Doutrina, garantida pelas armas, buscou na construção de um estado de exceção a tentativa de legalização. Neste contex to, a atividade repressiva, como um braço do Estado autoritário, carregava a concepção de autodefesa e de autoproteção do Estado contra os seus opositores.

A lógica se efetivou pela presença de um aparelho burocrático, e suas ramificações no tecido social, bem como pela fabricação do medo, caracterizando o inimigo e as formas de seu enfrentamento. Sua aplicação e o seu funcionamento, por exemplo, a partir de 1968, implicou na centralização dos diferentes órgãos de vigilância e no projeto de integração da prática policial, até então sob a responsabilidade dos estados, no intuito de agregar as forças policias com vista à segurança nacional. 


\section{A estrutura de vigilância e a formação dos agentes de informação}

Os órgãos de informação e de vigilância não foram exclusividade da Ditadura Militar, embora tenha sido neste período que ocorreu o aprimoramento e a ampliação dos aparelhos de controle social. O primeiro órgão de vigilância surgiu em 1927, sob a denominação de Conselho de Defesa Nacional (CDN). Fora criado para obter informações relevantes para a defesa da pátria. Apesar de possuir um caráter consultivo, serviu como instrumento de investigação e de vigilância dos operários, para coibir as agitações políticas e para espionar e identificar os inimigos do governo (FIGUEIREDO, 2005, p. 36-51). Getúlio Vargas o aprimorou dotando-o de assessoria técnica no intuito de torná-lo mais centralizado com representação dos órgãos nos ministérios civis. Com Vargas, o CND passou a se chamar Conselho de Segurança Nacional (CSN).

Somente na década de 1940, surgiu um órgão voltado para o serviço de informação: o Serviço Federal de Informações e Contrainformações (SFICI), vinculado ao CSN. Recolher e analisar sistematicamente informações relacionadas à defesa da nação e realizar o serviço de propaganda do país no exterior eram uma de suas funções. Nos anos de 1950, as atividades do SFICI foram regulamentadas assumindo uma estrutura mais técnica e operacional. Neste momento, seu objetivo era o de oferecer apoio ao Grupo de Estudos e Planejamento (GEP), criado, em 1958, para realizar ou promover estudos relativos à segurança nacional, além de elaborar as diretrizes e opinar sobre os problemas referentes às questões de segurança (QUADRAT, 2012).

Durante a existência do SFICI, foram realizadas operações responsáveis pelos grampos telefônicos, pelo controle de informações e de investigação de partidos políticos e de organização de classe. No início da década de 1960, o órgão sofreu mudanças na estrutura profissional coordenada pelo general Golbery do Couto e Silva, que pretendia fazer do órgão uma instituição mais eficiente com ramificações nas várias instâncias da sociedade por meio de um quadro pessoal profissional. A capacitação se daria por meio de cursos de formação na área de vigilância, e a obtenção de informações era uma de suas funções.

Em substituição ao SFICI, no dia 13 de junho de 1964, pela Lei 4.341, surgiu o Serviço Nacional de Informações (SNI) (LAGÔA, 1983, p. 19). Criado pelo marechal Humberto de Alencar Castello Branco e idealizado pelo general Golbery do Couto e Silva, a intenção era aprimorar o serviço de inteligência, suprir as deficiências institucionais dos órgãos anteriores e equipar o país de um moderno sistema preventivo que pudesse fazer frente às ações das esquerdas. Com um raio de alcance amplo e com maior investimento de verbas federais, o SNI coordenou toda a ação repressiva durante o Regime Militar. 
Vinculado à Presidência da República, suas atividades organizavam-se seguindo três importantes dimensões: 1) conjuntura brasileira: assessoria ao poder Executivo a partir da elaboração de estudos da situação política e econômica do país; 2) segurança nacional: atividades direcionadas para a identificação do inimigo; e 3) orientação e instrução dos membros da máquina repressiva, atividades voltadas para a formação e orientação dos agentes da repressão - orientá-los quanto suas ações e recrutar informantes para atuar nas várias instâncias da sociedade.

Em 1967, o presidente Costa e Silva criou o Centro de Informações do Exército (CIE), somando-se às atividades de informação e vigilância do SNI. Um dos seus idealizadores, o coronel Adyr Fiúza de Castro, comandou as ações do órgão com mãos de ferro. Infiltrou os agentes no movimento estudantil e nos sindicatos, além de articular ações de combate à subversão e à luta armada. Criou estratégias para grampear telefones e inserir oficiais nas universidades para agirem como estudantes e simpatizantes de esquerda. Segundo o próprio coronel, infiltrar oficiais treinados assegurava a eficácia da ação. Para ele, "o sargento era o melhor infiltrado, porque era um profissional. E não era preciso pagar extra; ele estava ali executando uma missão" (D’ARAÚJO; SOARES; CASTRO,1994, p. 39-40).

No início da década de 1970, integrando o aparelho repressivo do Estado, surgiu uma escola inteiramente voltada para a formação de analistas de informação, a Escola Nacional de Informações (ESNI). Inspirada nos currículos das principais escolas de informação da Alemanha, Inglaterra, Estados Unidos e França, a Escola incorporou os cursos de formação da ESG e de outros órgãos do Estado. O propósito era o de formar uma elite especializada em informação e contrainformação. Os cursos eram direcionados aos civis e aos militares e estavam organizados em três níveis: "A", "B" e "C". O primeiro se destinava a civis e militares que ocupassem funções de chefia; o curso B, alcançava os civis e militares com funções de informação de nível médio ou chefia de escalão intermediário; e, o C era para formar o quadro de funcionários responsáveis pela chefia das seções de informação: capitães, tenentes e sargentos. Além disso, cooperar com o desenvolvimento de uma doutrina nacional de informação e tornar-se uma referência em pesquisas na área de informação.

Dessa maneira, estruturou-se, no período da Ditadura, uma "comunidade de informação" com um conjunto de órgãos de informações civis e militares. Além das instituições oficiais, a "comunidade" fora composta por uma miríade de pessoas da sociedade dispostas a colaborar com o governo fornecendo informações e vigiando setores da sociedade. Por meio desse instrumento, a máquina repressiva estendeu os seus tentáculos 
por toda a sociedade conquistando adesão via propaganda mais restrita, disseminada por meio de panfletos e informativos.

Com a intensa mobilização de movimentos de protestos, como o estudantil, e a estratégia de resistência adotada por alguns segmentos da esquerda, como a luta armada, ocorreu o recrudescimento do Regime, tornando-se ainda mais violento (HUGGINS, 1998, p. 165-186). Para tanto, os militares aprimoraram e sistematizaram suas atividades com a criação de órgãos de planejamento, como o Grupo de Operações Especiais (GOE), e equipamentos especializados que controlavam a execução das medidas de repressão e buscavam articular todas as instâncias envolvidas. Um deles, o Destacamento de Operações de Informações - Centro Operações de Defesa Interna (DOI-CODI), criado pelo Exército, com o auxílio dos Estados Unidos, nasceu com a tarefa de planejamento para facilitar a coleta rápida de informações, identificar e capturar os potenciais grupos inimigos para destruí-los e neutralizá-los.

\section{O formulário}

A vigilância, como fora demonstrada, foi um aspecto estratégico para os militares, uma vez que sua função consistia em produzir informações sobre pessoas, movimentos sociais e grupos políticos, sobretudo subversivos, evitando possíveis ameaças ao governo militar. Para tanto, a confiabilidade das informações e a formação dos agentes assumiram preponderante papel no decorrer da Ditadura Militar. Neste aspecto, dois pontos merecem destaque. O primeiro diz respeito à eficácia e à confiabilidade das informações. Para isso, ainda nos tempos do SFICI e dos cursos de formação da ESG, um sistema fora criado para garantir o aperfeiçoamento das informações e a precisão das ações. Baseava-se no sistema letra-número:

\section{SISTEMA LETRA-NÚMERO}

Classificação da fonte

A - Fonte absolutamente idônea.

B - Fonte usualmente idônea.

$\mathrm{C}$ - Fonte razoavelmente idônea.

D - Nem sempre idônea.

E - Fonte inidônea,

F - Não pode ser julgada a idoneidade da fonte.
Veracidade da informação

1 - Informe confirmado por outras fontes.

2 - Informe provavelmente verdadeiro.

3 - Informe possivelmente verdadeiro.

4 - Informe duvidoso.

5 - Informe provável.

6 - A veracidade do informe não pode ser provável.

Quadro 2: Instrução particular que regula o funcionamento da Subseção de Operações (SSOP), de 15 set. de 1960. Do Sfici. Confidencial. ArN/X-9 
Quanto mais próximo da letra A e do número 1 a informação estivesse, mais o seu grau de idoneidade e de veracidade era atestado. A classificação permitia que a informação fosse investigada com maior acuidade de forma a garantir o sucesso da ação dos agentes dos órgãos de repressão. O padrão compôs, posteriormente, os relatórios de informações que se seguiram com o aprimorado dos serviços de informação durante a Ditadura Militar. Geralmente, a classificação C era a mais comum devido à presença de oficiais preparados nas investigações. Porém, todas as informações eram arquivadas, pois serviriam de bases para possíveis investigações.

As instruções e orientações quanto à obtenção das informações e a identificação das possíveis ameaças, de alguma maneira, chegavam às Delegacias de Ordem Política e Social (DOPS). Embora a literatura sobre o tema demonstre uma maior centralização do sistema de informação e vigilância a partir da década de 1970, não se pode negar que, em algum nível e de maneira distinta, este processo já se presenciava antes do período mencionado. De fato, é importante ressaltar que fora no início dos anos de 1970 que o SNI passou a subordinar as DOPS, no mesmo momento em que se dá o processo de recrudescimento do Regime Militar. Os agentes deveriam seguir as orientações no intuito de identificar atividades na cidade e no campo que fossem consideradas suspeitas. Tendo em vista tais elementos, os agentes deveriam levar em conta que o informe poderia ser "atos ou fatos aparentemente sem importância ocorridos com pessoas ou organizações, que deveria se observar, pois a soma de todos eles resultaria numa informação" (D’ARAÚJO; SOARES; CASTRO,1994, p. 46-47).

A partir dos anos de 1970 passou-se a exigir o Plano Nacional de Informação. O propósito era o de intensificar as atividades de investigação e conduzi-las aos órgãos centrais, como o SNI. Surgiu no contexto de burocratização dos aparelhos do Estado, que incluía, além das ações de repressão, o sistema político e econômico (CODATO, 1994). Para tanto, cobrava-se dos agentes o cumprimento de metas. As informações deveriam seguir um plano de metas e chegar, periodicamente, aos órgãos responsáveis. Um exemplo foi o Ofício encaminhado aos órgãos de vigilância do Paraná, em 1971:

\begin{abstract}
A Agência de Curitiba do SNI, em cumprimento ao Plano Nacional de Informações (Decreto n 66.732 de 16. Jun.70) deverá levar, periodicamente ao conhecimento do Exmo. Senhor presidente da República, dados referentes aos campos Político, Econômico, Militar e Psicossocial, tendo em vista a aplicação do Poder Nacional (DOPS-SNI, 1971).
\end{abstract}

Uma consequência desse processo foi a produção de relatórios redigidos pelos agentes de segurança seguindo um método científico. A precisão nos dados, a exatidão na identificação era observada com rigor máximo. A intenção era produzir informações que poderiam, no futuro, produzir a culpabilidade dos vigiados. Em determinados momentos, os relatórios classificaram um número alto de pessoas que, segundo as informações, 
supostamente participavam de atividades subversivas. Em um deles, encontramos trinta nomes apenas em quatro páginas de relatório. Cada um deles com o seu respectivo endereço, filiação, origem e profissão. Além disso, exigia-se que sobre os investigados fossem também auferidos sua filiação ideológica e política (DOPS-SNI. Pedido de busca).

Para que essa máquina pudesse funcionar, o papel dos colaboradores, em diferentes níveis, foi essencial para o fornecimento de dados necessários aos órgãos do governo. $\mathrm{O}$ fato gerou um aumento no número de informações e os cidadãos logo passaram a ser vistos como suspeitos. Qualquer ato ou indivíduo era passível de investigação. A matriz da vigilância eram os informes que compreendiam toda informação fornecida pelos agentes e informantes, mesmo aquela cujo conteúdo não tinha sido investigado e nem confirmado pelos serviços de inteligência. Tudo fazia parte do arquivo da repressão.

\section{O Informante}

O ponto de partida para este item será o texto de Bernardo Kucinski (2014), $K$ : relato de uma busca. Através da narrativa ficcional e linear, o autor apresenta um episódio traumático que afetou de forma indelével toda a sua família, o desparecimento de sua irmã, Ana Kucinski. A busca incessante do pai, o senhor K, pela filha desaparecida, leva-o a percorrer os episódios que marcaram a Ditadura Militar, ao mesmo tempo em que revela traços da vida da filha não conhecidos pelos familiares como a sua atividade de professora na Universidade de São Paulo (USP) e a sua militância política na Aliança Libertadora Nacional (ALN).

Na trajetória angustiante, marcada pelo silêncio e pela incerteza, a saga do senhor $\mathrm{K}$, no exercício de imaginação do autor, dá voz à subjetividade do inimigo na figura do delator, do informante, do torturador e dos agentes da repressão. Aqui, a ficção, recurso de que se apropria o autor, jamais pode ser concebida como mentira. A forma como descreve, em formato de capítulos/conto, busca testemunhar o horror pelo qual sua família foi vítima e desvendar os subterrâneos da Ditadura. Interessa, na narrativa, particularmente o modo pelo qual aqueles que perpetraram o horror são descritos, entre eles, a figura do informante e do colaborador.

O informante ou o colaborador constitui uma figura emblemática na cadeia do sistema repressivo do Estado. A compreensão de suas práticas carece de análises que sejam capazes de lançar luz à zona, ainda obscura, das motivações que levam alguém a compactuar, de forma direta ou indireta, com determinadas forças de comando e sistemas 
causadores de violência. É um assunto complexo porque toca o universo psíquico e a subjetividade dos indivíduos. Isso tem a ver com as crenças, atitudes ou valores que levam o indivíduo à ação e com as necessidades psicológicas que oferecem condições para que aceite uma ideia.

Um estudo, dirigido por Theodor Adorno (1965, p. 19-36), publicado nos Estados Unidos após a Segunda Guerra, pode indicar algumas pistas para compreender esse tipo de comportamento. $\mathrm{O}$ autor tratou de mostrar, no contexto pós-totalitarismo, como alguns indivíduos apresentavam certa pré-disposição para o antissemitismo. No fundo, Adorno pretendia compreender, com auxílio da psicologia e da psicanálise, o preconceito social e o surgimento do homem autoritário. Em A personalidade autoritária, Adorno nos mostra que as crenças antissemitas expressam as necessidades de pessoas que, privadas de figuras fortes de autoridade na infância, sentem-se fraca e querem encontrar figuras estranhas a quem culpar.

Os estudos realizados pelo sociólogo Richard Sennett (2001, p. 40) apontam uma ligação entre a repressão infantil e sua relação na vida adulta. Em outras palavras, a primeira infância se configura como uma importante fase na vida do indivíduo porque ela exerce impacto em sua vida adulta. A imagem de um genitor é projetada pelos adultos em outros adultos constituindo aquilo que o autor chama de uma necessidade de autoridade, reflexo de uma ausência marcada ainda na infância. Tal força pode se apresentar a partir de duas formas: uma psicológica, configurando o que leva o indivíduo a sentir a necessidade desesperada de força e, outra, a histórico-social, que molda a maneira de expressar essa necessidade. Ela desenvolve uma estrutura dentro do indivíduo oferecendo as condições que estimulam ou retardam a persistência desses padrões infantis.

Para Adorno (1965, p. 32), a intersecção entre essas forças forma a personalidade autoritária. Por personalidade entende-se a organização de forças mais ou menos duradouras dentro do indivíduo. São elas (instintos, desejos, impulsos emocionais) que ajudam a determinar a resposta a várias situações perceptíveis pelo comportamento. $\mathrm{O}$ autoritarismo, por sua vez, refere-se a um sistema de atitudes que consiste em uma série de sentimentos antidemocráticos correlatos entre si e que compõe a estrutura da personalidade (TEIXEIRA; POLO, 1975). O homem autoritário demonstrava ser um indivíduo esclarecido, supersticioso, individualista e inclinado a se submeter ao poder e à autoridade. Etnocêntrico, ele denota uma aversão a outros grupos étnicos. O aspecto autoritário, nessa lógica, seleciona estímulos ideológicos que o clima de sua época propicia. Muitos deles são adquiridos no processo de socialização.

A partir dessa concepção psicossocial, a preocupação de Adorno era a de estudar 
o sujeito potencialmente fascista identificando as forças subjetivas que favorecem a aceitação do fascismo e, ainda, compreender a estrutura que os tornaram suscetíveis à propaganda antidemocrática. Sabendo que o fascismo precisa das massas e da cooperação da maioria das pessoas, a propaganda só foi eficaz na medida em que aspectos antidemocráticos já existiam na grande massa das pessoas. Para autores como Reich (1974), a atração pelo discurso fascista foi possível porque houve uma identificação da população com os líderes do movimento fascista. Na metáfora psicanalítica do pai, eles substituíram o lugar do pai autoritário e, por meio da propaganda, deixaram nos seus liderados a necessidade de encontrar um bode expiatório para descarregar as frustrações e, na figura do líder, satisfazer sua necessidade de autoridade.

O estudo de Adorno foi importante porque abordou questões sobre o indivíduo, à época, pouco estudado. É preciso deixar claro que sua pesquisa inseriu-se num contexto americano do pós-guerra com referências políticas e sociais distintas daquele instituído pela Ditadura Militar brasileira. Entretanto, os apontamentos sobre o caráter autoritário e a necessidade de força por parte de alguns indivíduos parece útil para se compreender, no caso do informante e do colaborador, o apego a símbolos que representam autoridade. $\mathrm{O}$ fascínio pela ordem, pela defesa da nação, do moralismo, da família, coloca-os numa posição perversa que implica a negação no outro, que é incapaz de realizar em si. O outro é aquele capaz de levar à fragmentação do corpo social, o elemento de estabilidade e segurança (ENRIQUEZ, 2007, p. 188-189).

Nesse sentido, a descrição de Kucinski ilumina a nossa compreensão sobre a figura do informante. No capítulo Os informantes, a primeira característica do informante é a de ser um cidadão comum, alguém que frequentava, de maneira imperceptível, os espaços comuns de sociabilidade. Cotidianamente, lá estava ele nos ambientes de circulação pública: a panificadora, o boteco da esquina, o mercadinho, a escola, a universidade, a igreja. Um mundo paralelo, uma zona desconhecida. $\mathrm{O}$ autor descreve,

\begin{abstract}
Além do mundo que se vê e nos acalma com seus bons-dias boas-tardes, como vai tudo bem, há outro que não se deixa ver, um mundo de obscenidade e vilanias. É nele que vicejam os informantes. Não fosse o sequestro da filha, K. nunca teria percebido esse outro mundo tão perto de si. No entanto, eles sempre ali estiveram, sorrateiros, os informantes da polícia (KUCINSKI, 2014, p. 29).
\end{abstract}

Na trajetória dos indivíduos comuns, o informante também se torna um deles. Pouco conhecido, quase invisível caminhava pela esquina, tropeçava numa senhora, acendia um cigarro, tomava um café. De bom dia à boa tarde, socializava-se com o vizinho, comentava o jogo de futebol do dia anterior. Sabia-se pouco sobre sua vida. Indivíduos de pouca ou sem nenhuma fama, desciam a calçada da esquina, dobravam a rua com o olhar que se estendia a tudo à sua volta. Kucinski descreve o informante como um desconhecido 
cuja reação era para quem descobria sua função, uma surpresa: "Espantoso, Caio informante da polícia. Surpreso e pressuroso, K. escreve o nome e a idade da filha num guardanapo de papel. Professora de química da Universidade de São Paulo, acrescenta” (KUCINSKI, 2014, p. 30).

À condição de sem fama, um desconhecido, somava-se ao informante outra característica, a capacidade de estar onde todo mundo está e em espaços inusitados. Compartilhava-os com as pessoas, cujas vidas eram o objetivo de investigação. Precisava conhecer sua sociabilidade: amigos e vizinhos, colegas do futebol e de baralho. Por priorizarem os ambientes comuns de maior circulação de pessoas, era preciso que estivessem em toda parte:

Uma padaria, continua o português, não é só um lugar de comprar pão, é um clube, um ponto de encontro, como as farmácias do interior. $\mathrm{O}$ senhor sabe quantas conversas rolam no balcão? Na minha padaria passam duas mil pessoas por dia e mais de três mil aos sábados e domingos. As padarias são muito úteis à polícia, explica Amadeu. [...] Se o Caio e o Amadeu são informantes, espias deve está em toda parte, raciocinou K., perplexo (KUCINSKI, 2014, p. 31).

O informante era alguém que atuava em nome de um outrem. Sua função era mantê-lo informado ao traçar as linhas por que percorreu o informado. Agir em nome de outro, assegurá-lo o controle da informação, e sobre esta deliberar ação necessária. Era o braço do regime e atuava ali onde ele não poderia estar. Ele próprio era parte desse sistema em cujo poder estendia-se capilarmente, para usar as palavras de Michel Foucault (1979, p. 179-191), ali onde ele mesmo se exercia, nas relações de sociabilidades diárias. Um poder micro que se inseria, apossava-se, vigiava e observava os indivíduos. O informante alimentava a grande máquina de engolir informação, os órgãos de vigilância e informação do Estado.

Como forma de controle, a eficácia da informação se dava na medida em que aquele que a controlava poderia usá-la contra a pessoa investigada. Os informes, mantidos em segredo, garantiam aos agentes policiais agir em sigilo como se a normalidade não fosse ferida. O segredo sobre os corpos desaparecidos, o segredo sobre a informação tirada sob o grito e a dor, o segredo da informação reiterou aos militares poder e controle.

[...]. Eis os espias de novo em toda parte. Ou sempre estiveram? Começa a achar que sempre estiveram; o Governo podia usar ou não as informações, mas os informantes nunca pararam de informar. Se fosse um Governo maligno, como o de Getúlio, usava. Se fosse benigno, usava menos. Pois o não descobriu o esconderijo da Olga e de tantos outros através dos informantes? O que ele fez com a Olga foi repugnante (KUCINSKI, 2014, p. 34).

Infiltrado em diferentes grupos, instituições e segmentos sociais, o informante era aquele convidado a suspeitar de tudo e de todos. Na lógica da "guerra psicológica", a ameaça rondava todas as partes e o medo, inserido na própria sociedade, criava nas pessoas uma paranoia contínua. Os militares, por exemplo, matriculavam oficiais em cursos 
universitários para que pudessem investigar o movimento estudantil. Criavam-se laços sociais com os estudantes, aproximavam-se de suas ações e se fingiam serem, os informantes infiltrados, defensores das ideias de esquerda para que pudessem ser aceitos mais facilmente pelo grupo.

Desconfiar, nesse sistema, significava apontar para indícios, fossem eles quais fossem, mas que pudessem representar um tipo anormalidade. Além disso, o olhar atento era quesito indispensável. O informante deveria ser um bom observador, atentar-se para cada palavra proferida, para cada atitude suspeita e para cada indivíduo cuja ideia soava contrária às regras estabelecidas.

A galeria é estreita, de dois pavimentos. Apontam a K. o dono, um rapaz de calças jeans e
tênis. K. o aborda e se apresenta, muito rápido. O jovem se surpreende, logo se recobra, pega
K. pelo braço, e o conduz à rua devagar; diz que a loja é barulhenta, não dá para conversar.
Na rua diz para K. caminhar enquanto fala: ele está ouvindo. Teme os empregados da loja,
avalia K. Lembrou-se das amigas da filha empurrando-o para o jardim. Percorrem a José
Paulino até o fim, e voltam pela calçada oposta, K. falando, o informante escutando. Vez ou
outra, o informante olha de soslaio para trás e duas vezes interrompe K. tentando descobrir
quem o mandara (KUCINSKI, 2014, p. 34).

Nota-se que, Bernardo Kucinski constrói, em sua narrativa, os traços do perfil do informante. O informante é um indivíduo comprometido com o poder estabelecido. Assumem como verdade incontestável os valores que lhes são transmitidos, especialmente os referentes à proteção da pátria e da nação. O informante se sente responsável por tal tarefa e, por medo ou por crença, acredita fazer comungar e fazer parte dos desígnios da comunidade dos escolhidos. Como um "em toda parte" ele está alerta espreitando suas vítimas e, por vezes, disseminando notícias controversas para burlar a atenção das pessoas e, em outros momentos, demonstrando-se atenciosos para com os seus investigados: "Repassou preocupado o que havia revelado aos ouvidos traiçoeiros dos informantes. Os mais perigosos eram os mais prestimosos, como o Caio, que ouviam até o fim e prometiam" (Idem, 35).

Além do informante profissional, Kucinski também descreve o colaborador comum, aquele que se dispôs, de forma espontânea, a contribuir com o poder estabelecido. Geralmente eram pessoas com um forte apelo conservador e eram motivadas, em grande medida, pelos símbolos comoventes da nação. Alguns deles apresentavam-se espontaneamente aos órgãos de vigilância e de repressão. Caso do estudante que endereçou uma carta à DOPS no intuito de saber como tornar-se um agente e prestar-lhes serviço (Carta ao delegado da DOPS).

Atitudes como estas eram importantes para os militares, pois poderiam contar com o apoio de pessoas inseridas no meio estudantil, ambiente onde ocorriam focos de oposição ao regime. Infiltrar-se nas instituições de ensino, seja por oficiais das Forças Armadas ou 
por informantes civis, permitia vigiar os grupos ou as atividades de indivíduos por dentro, ou seja, entender como eram arquitetadas as oposições para miná-las atuando preventivamente. Os informes poderiam chegar de forma anônima. Em muitos casos feitos em forma de cartas, por indivíduos comuns. Nelas estavam descritas o endereço da residência e do trabalho do indivíduo denunciado, o tipo de atividade que praticava e os lugares que costuma frequentar sua orientação política e ideológica (ARQUIVO PÚBLICO DO PARANÁ. Informes, 1964-1977). Por mais comuns que pudessem parecer os informes, de algum modo, era solicitado um tipo de investigação.

Muitas vezes as denúncias eram encaminhadas para os órgãos cuja tarefa não era de investigação, como o Exército. No entanto, eram encaminhadas ao responsável pela segurança pública do Estado, a exemplo do que fez o general Dario Coelho ao receber uma lista com cerca de 10 nomes de supostos comunistas e professores chamados de subversivos (ARQUIVO PÚBLICO DO PARANÁ. Ofício, 1964-1977). Os informes, independentemente de sua origem, eram arquivados e, na maioria das vezes, investigados pelos agentes. Comuns eram as denúncias relacionadas a práticas atreladas à manutenção da ordem. Os informantes responsáveis por tais denúncias acreditavam prestar um bom serviço ao país. Nesse sentido, a propaganda ufanista da década de 1970 fora capital. Por meio dela o amor à pátria, a crença nos militares como regeneradores dos males da nação e o ideal de brasileiro confundiam-se, como atesta algumas expressões encontradas nos documentos e arquivos do sistema repressivo: "A Revolução foi feita para corrigir. Devemos fazer o possível para chegarmos nessa meta. Isto é dever de todo bom brasileiro!" (ARQUIVO PÚBLICO DO PARANÁ. Informantes, 1964-1977).

Ressalta-se o papel exercido pelos informantes comuns (Figura 1), geralmente de classificações "D", "E" e "F", oriundos de diferentes segmentos da sociedade. Estavam dispostos a fornecer informes, dados pessoais de qualquer pessoa que representasse algum perigo. Exerciam a vigilância ali em seus espaços, como descreveu Kucinski, suspeitando de tudo e de todos. Neste império do medo, inúmeros nomes chegavam à DOPS, como demonstra o bilhete encaminhado aos agentes da repressão com nomes de pessoas que atuavam na resistência ao regime: 


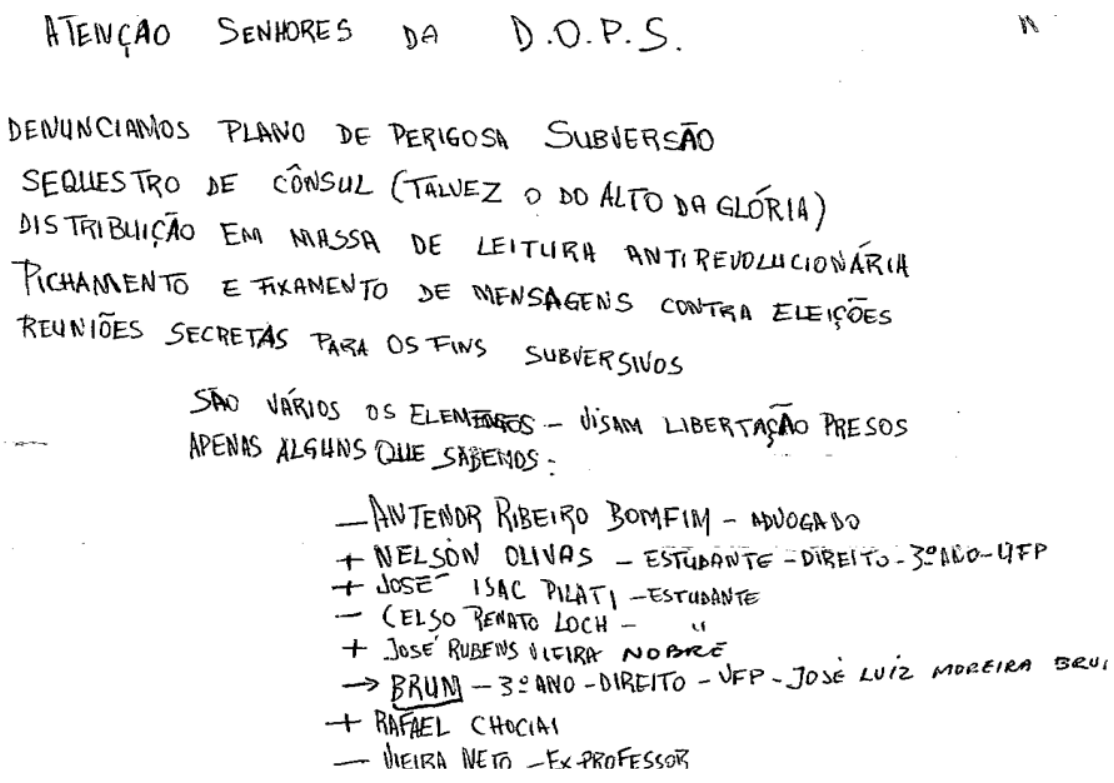

Figura 1: Denúncias anônimas. (ARQUIVO PÚBLICO DO PARANÁ. Informantes, 1964-1977).

Algumas denúncias eram motivadas por vinganças ou fatos irrelevantes, estes logo sem atenção dos militares. Mas, uma série delas era investigada em razão da natureza das ações dos suspeitos. Dos nomes citados, dois possuem uma longa ficha na DOPS, Nelson Olivas (DOPS, 1972) e José Isac Pilati (DOPS, 1970). Na pasta Informante, composta por cartas, bilhetes e relatórios de supostos inimigos do Estado, aqui analisados, dos 110 nomes descritos no documento, mais de vinte por cento tinham fichas individuais na DOPS ou foram presos. O que demonstra que, embora houvesse filtragem dos informes pelos agentes especializados, um número expressivo de pessoas tinha as suas vidas aprisionadas pela máquina repressiva (ARQUIVO PÚBLICO DO PARANÁ, 1964-1977). Uma tarefa possível porque a máquina repressiva encontrou na sociedade indivíduos dispostos a apoiar e a colaborar com o Regime. Em muitos casos, aquele que fornecia informação, o colaborador, tinha, em algum nível, um tipo de relação social com quem era denunciado.

\section{Considerações finais}

O investimento na formação de agentes, militares e civis, para atuarem nos serviços de inteligência e de repressão política e na criação de uma estrutura repressiva com órgãos responsáveis pela vigilância, aprisionamento e combate às ações subversivas, caracterizou a Ditadura Militar. Esse aparato foi mobilizado no intuito de garantir aos militares a gerência do sistema político, caracterizando um estado de exceção no Brasil. Para tanto, o aprimoramento do aparelho repressivo e a promulgação de Leis, com forte inclinação à violência, garantiram o controle e a centralização das decisões políticas nas mãos do 
Executivo. Nesta lógica, o combate à subversão, por meio de uma "guerra psicológica", colocava a sociedade em constante alerta. Nesta visão, os cidadãos tornaram-se possíveis ameaças e, vigiá-los de forma eficaz, era o que almejavam os militares.

Nesse contexto, exerceu papel preponderante para a máquina repressiva, a formação dos agentes da repressão e o processo de fabricação do informante. Figura recorrente entre os agentes do Estado, o informante serviu para descobrir e desmantelar focos de oposição e identificar indivíduos considerados subversivos pelo Estado. Inseridos na sociedade, instituições públicas e privadas, escolas e espaços públicos, os informantes, imbuídos de valores morais de caráter tradicional, acreditavam ser responsáveis pela defesa da nação e, em nome desse ideal, eles agiam conforme as demandas solicitadas pelos militares.

Essa análise nos leva ao entendimento de que o Regime Militar se constituiu como tal porque encontrou na sociedade grupos e indivíduos dispostos a colaborar com o poder constituído. O exame dessas discussões, na tentativa de entender o período de autoritarismo no Brasil, aponta para novos desafios. Um deles é o de provocar fissuras no modo pelo qual o passado da Ditadura fora compreendido. Outro é o de pensá-lo criticamente no sentido de abrir caminhos para outras possibilidades de análises e de leituras capazes de vencer as diferentes formas de dominação, a repressão e a violência.

\section{Referências}

ADORNO, T. La personalidad autoritaria. Buenos Aires: Editorial Proyección, 1965. AGAMBEN, G. Estado de exceção. São Paulo: Boitempo, 2004.

AGAMBEN, G. Homo Sacer: o poder soberano e a vida nua. Belo Horizonte: Editora UFMG, 2007.

ARENDT, H. Sobre a violência. Rio de Janeiro: Civilização Brasileira, 2009.

ARQUIVO PÚBLICO DO PARANÁ. Informantes, 1964-1977. BR PRAPPR.PB004.PT 797.94.

ARQUIVO PÚBLICO DO PARANÁ. Informes oriundos de denúncias anônimas. Curitiba. Informantes, 1964-1977. BR PRAPPR.PB004.PT 797.94.

ARQUIVO PÚBLICO DO PARANÁ. Ofício n ${ }^{\circ}$ 140-E2. Assunto: informes. ARQUIVO PÚBLICO DO PARANÁ, Curitiba. Informantes, 1964-1977. BR PRAPPR.PB004.PT 797.94.

ARQUIVO PÚBLO DO PARANÁ. Lista de suspeitos. Curitiba. Informantes, 1964-1977. BR PRAPPR.PB004.PT 797.94. 1964-1977.

BRASIL. Ato Institucional No 2 (1965). Brasília, DF: Presidência da República, 27 de Outubro de 1965.

Carta ao delegado da DOPS. ARQUIVO PÚBLICO DO PARANÁ, Curitiba. Informantes, 1964-1977. BR PRAPPR.PB004.PT 797.94.

CODATO, A. N. O golpe de 1964 e o regime de 1968: aspectos conjunturais e variáveis históricas. História: Questões \& Debates, Curitiba, n. 40, p. 11-36, 2004. Editora UFPR. CODATO, Adriano Nervo. Centralização política e processo decisório: o governo Geisel em perspectiva. Revista de Sociologia e Política, n. 2, 1994, p. 57-78. 
D'ARAUjO, M. C.; SOARES, G. A. D.; CASTRO, C. (Orgs.). Os anos de chumbo: a memória militar sobre a repressão. Rio de Janeiro: Relume-Dumará, 1994.

DOPS. José Isac Pilati. Ficha Individual nº FI 32.071. DOPS. Arquivo Público do Paraná, Curitiba, 1970.

DOPS. Nelson Olivas. Ficha Individual nº FI 28.891. DOPS. Arquivo Público do Paraná, Curitiba, 1972.

DOPS-SNI. Ofício no 201/ACT/SNI. ARQUIVO PÚBLICO DO PARANÁ, Curitiba. DOPS-SNI. 1971. N. 003823.

DOPS-SNI. Pedido de busca n. 082/ACT/SNI/72. ARQUIVO PÚBLICO DO PARANÁ, Curitiba. DOPS-SNI. 1971. N. 003823.

ENRIQUEZ, E. As figuras do poder. São Paulo: Via Lettera Editora e Livraria, 2007.

FOUCAULT, M. Microfísica do poder. Rio de Janeiro: Graal,1979.

GURGEL, J. A. A. Segurança e Democracia: uma reflexão política sobre a doutrina da Escola Superior de Guerra. Rio de Janeiro: Biblioteca do Exército; Livraria José Olympio Editora, 1975.

HUGGINS, M. K. Violência urbana e privatização do policiamento no brasil: uma mistura invisível. CADERNO CRH, Salvador, v. 23, n. 60, p. 541-558, Set./Dez. 2010.

KUCINSKI, B. Abertura: a história de uma crise. São Paulo: Ed. Brasil Debates, 1982.

KUCINSKI, B. K. - Relato de uma busca. São Paulo: Cosac Naify, 2014.

LAGÔA, A. SNI: como nasceu como funciona. São Paulo: Editora Brasiliense, 1983.

MORIN, E. 1968-2008: o mundo que eu vi e vivi. In: AXT, G.; SCHÜLER, F. L. (Orgs.). Fronteiras do pensamento: ensaios sobre cultura e estética. Rio de Janeiro: Civilização Brasileira, 2010.

NAPOLITANO, M. 1964: história do regime militar brasileiro. São Paulo: Contexto, 2014. NODARI, A. Censura: ensaio sobre a "servidão imaginária". 252 p. Tese (Doutorado em Literatura), Universidade Federal de Santa Catarina, Centro de Comunicação e Expressão. Florianópolis-SC, 2012.

QUADRAT, S. V. A preparação dos agentes de informação e a ditadura civil-militar no Brasil (1964-1985). Varia História, Belo Horizonte, vol. 28, n 47, p. 19-41: jan./jun. 2012. REICH, W. Psicologia de massa do fascismo. Porto: Escorpião, 1974.

SENNETT, R. Autoridade. Rio de Janeiro: Record, 2001.

TEIXEIRA, J. B. de C.; POLO, A. A personalidade autoritária. Componentes para uma gênese psicológica. Arq. Bras. Psic. Apl. Rio de Janeiro 27(4), 47-69, out./dez. 1975.

Recebido: 30/05/2019

Aceito: 02/07/2019

Publicado: 04/09/2019

\section{Notas}

\footnotetext{
${ }^{i}$ Doutor em História pela Universidade Federal do Paraná (2016). Atualmente é professor magistério superior da Universidade Federal do Sul e Sudeste do Pará. E-mail: reginaldo.cerqueira@unifesspa.edu.br
} 